\title{
Geociências
}

\section{Feições intempéricas em rochas alcalinas félsicas de Nova Iguaçu, RJ}

\author{
(Weathering fabrics in felsic alkaline rocks of Nova Iguaçu, \\ State of Rio de Janeiro, Brazil)
}

\begin{abstract}
Akihisa Motoki
Depart. de Mineralogia e Petrologia Ígnea, Univ. do Estado do Rio de Janeiro. E-mail: amotoki@yahoo.com Rodrigo Soares

Depart.de Mineralogia e Petrologia Ígnea, Univ. do Estado do Rio de Janeiro.E-mail: roddrigoss@yahoo.com.br Susanna Eleonora Sichel Depart. de Geociências, Laboratório de Geologia do Mar, Univ. Federal Fluminense. E-mail: susanna@igeo.uff.br José Ribeiro Aires

ABAST/Petrobras.E-mail: aires@petrobras.com

Marcela Lobato

Depart. de Mineralogia e Petrologia Ígnea, Univ. do Estado do Rio de Janeiro. E-mail: marcela_lob@hotmail.com
\end{abstract}

\section{Resumo}

Esse artigo apresenta descrições de campo e considerações genéticas de feições intempéricas observadas em rochas alcalinas félsicas de Nova Iguaçu, RJ, com atenção especial aos clastos traquíticos de brecha vulcânica. Observam-se dois tipos de feições notáveis: “case hardening”, o endurecimento da superfície da rocha por cimentação dos minerais intempéricos com o auxílio de hidróxidos dissolvidos na água superficial percolante; “dissociação mineral”, o intemperismo seletivo de minerais e a conseqüente formação de cavidades na superfície da rocha. Nos afloramentos intemperizados das brechas, o case hardening forma saliência centimétrica dos clastos traquíticos sobre a superfície da matriz. Os clastos maiores do que $30 \mathrm{~cm}$ mostram a feição de saliência e reentrância na borda, que é originada do contraste entre a superfície endurecida e a subsuperfície não endurecida. Esses clastos têm suave saliência central cuja subsuperfície é composta do núcleo sem alteração. A lixiviação dos fenocristais de feldspato alcalino forma numerosas cavidades na superfície intemperizada de clastos de traquito porfirítico, gerando uma estrutura pseudovesicular, porém, na subsuperfície, a rocha menos alterada com textura maciça está presente. Esse fato demonstra que essas não são bombas, spatter ou escória. Essas observações são desfavoráveis à hipótese do Vulcão de Nova Iguaçu, que adota uma origem extrusiva dos clastos como um argumento fundamental.

Palavras-chave: Case hardening, dissociação mineral, pseudovesicular, brecha, clasto, traquito, Nova Iguaçu.

\begin{abstract}
This paper presents the field description and genetic consideration of weathering fabrics observed in the Nova Iguaçu felsic alkaline rocks, State of Rio de Janeiro, Brazil, with special attention to trachytic clasts of volcanic breccia. Two types of notable fabrics are observed: "case hardening", the rock surface induration by cementation of weathered minerals with the help of the hydroxides dissolved in the surface water; and "mineral dissociation", the selective mineral weathering and consequent formation of cavities on the rock surface. On the weathered outcrops of the breccia, case hardening forms centimetric positive relief on the trachytic clasts of the matrix surface. Clasts larger than $30 \mathrm{~cm}$ show positive and negative reliefs along the rim, which are originated from the contrast between the hardened surface and relatively soft subsurface. They have a gentle central prominence underlain by a fresh rock core. The elimination of alkaline feldspar phenocrysts forms numerous cavities on the weathered surface of the trachyte clasts, generating a pseudovesicular structure, but in the subsurface, less weathered massive rock can be found. This fact demonstrates that these clasts are not bomb, spatter or scoria. These observations are unfavourable to the hypothesis that the Nova Iguaçu complex is a volcano, which is based on the extrusive origin of the clasts as a fundamental argument.
\end{abstract}

Keywords: Case hardening, mineral dissociation, pseudovesicular, breccia, clast, trachyte, Nova Iguaçu. 


\section{Introdução}

No Estado do Rio de Janeiro, ocorrem dezenas de complexos intrusivos de rochas alcalinas félsicas do final do Cretáceo ao início do Terciário (Ulbrich \& Gomes, 1981). Essas rochas são compostas, principalmente, de álcali sienito e nefelina sienito e, subordinadamente, traquito, fonolito, lamprófiro e rochas piroclásticas.

As rochas piroclásticas presentes na borda nordeste do complexo sienítico do maciço Mendanha, situadas na proximidade da cidade de Nova Iguaçu (Figura 1), foram noticiadas por Klein e Vieira (1980a) e interpretadas como formadoras de um vulcão extinto. As rochas piroclásticos são compostas de tufo, lapilli e aglomerado, cuja matriz apresenta alto grau de soldamento (Klein \& Valença, 1984; Klein et al., 1984; Klein 1993), com existência de feições similares a spatter, escória, pillow e bomba de crosta-de-pão (Klein et al., 2001).

Por outro lado, existem opiniões controversas ao modelo do vulcão. Motoki et al. (2004; 2005; 2006a) e Motoki e Sichel (2006) apresentaram argumentos de que as rochas anteriormente citadas correspondem aos materiais que preencheram condutos e fissuras vulcânicos.

As rochas alcalinas de Nova Iguaçu, sobretudo as brechas vulcânicas, apresentam feições peculiares originadas de intemperismo, com atenção especial de case hardening e dissociação seletiva de minerais. Essas rochas são importantes para interpretação de forma de ocorrência geológica das rochas piroclásticas. No presente artigo, os autores apresentam descrições das feições intempéricas e considerações sobre sua gênese.

\section{Feições intempéricas características}

O intemperismo químico altera os minerais constituintes da superfície de rochas. Por meio da decomposição dos minerais máficos e feldspatos, ferro, magnésio, cálcio e sílica são lixiviados. Os materiais remanescentes são altamente aluminosos e silicáticos, podendo ter resistência mecânica dos próprios minerais, porém não há coesão. Dessa forma, a desintegração da rocha ocorre, normalmente, a partir da superfície.

Por outro lado, existem certos casos em que a superfície intemperizada adquire resistência superior à subsuperfície também alterada. Os materiais lixiviados dissolvidos na água superficial, tais como ferro, magnésio e sílica, possivelmente enxofre, cimentam os minerais intempéricos sílica-aluminosos, principalmente na forma de hidróxidos. O endurecimento da superfície, através desse processo, é denominado "case hardening" (Dorn, 2004, Figura 2A). A relativa fragilidade da subsuperfície é chamada, eventualmente, de “core softening”.

Esse fenômeno ocorre em vários tipos de rochas, preferencialmente de composição silicática e/ou aluminosa, tais como riolito, dacito, traquito, arenito e quartzito. Nos casos da cimentação por sílica, o efeito do endurecimento por case hardening, através da formação de calcedônia, é notável (Campbell, 1999). Recentemente, a sonda marciana Spirit observou case hardening na superfície das rochas presentes na cratera Gusev, formada por impacto de meteorito. $\mathrm{O}$ fenômeno é atribuído ao intemperismo mediante a água superficial desse planeta (Farmer, 2005).

Na superfície endurecida por case hardening, sobretudo de rochas alcalinas félsicas, o intemperismo afeta, seletivamente, os minerais. A nefelina é um mineral muito sensível ao intemperismo químico e é alterada em natrolita e cancrinita. Em afloramentos de nefelina sienito e fonolito e gnaisse de composição nefelina sienítica, a nefelina intemperizada destaca-se pela cor branca sobre o fundo escuro da rocha intemperizada. Após a lixiviação de nefelina, formam-se cavidades na superfície da rocha.

Fenômeno similar ocorre, também, na alteração seletiva de fenocristais de feldspato alcalino de rochas traquíticas, dacíticas e riolíticas. O feldspato alcalino é, quimicamente, mais resistente do que a nefelina. Entretanto, a água infiltra, ao longo dos planos de clivagem, e o intemperismo avançam, facilmente, até o núcleo do mineral. Com o auxílio dessa alteração, ocorrem a desintegração física do feldspato alcalino e a formação das cavidades na superfície da rocha (Figura 2B). Caso esse processo seja avançado, a superfície intemperizada apresenta aparência similar à estrutura vesicular. Nesse trabalho, tal feição é chamada de “estrutura pseudovesicular”.

Na literatura geológica consultada pelos autores, não há registro dos processos de intemperismo anteriormente citados, devido, provavelmente, à escassez de ocorrência de rochas alcalinas félsicas na superfície da Terra. No presente trabalho, os autores chamam esse fenômeno intempérico de "dissociação mineral".

\section{Intemperismo de clastos das rochas piroclásticas}

As rochas piroclásticas de Nova Iguaçu apresentam, quatro graus diferentes de intemperismo: ausente, baixo, médio e alto.

Os afloramentos intactos de rochas piroclásticas são encontrados em pedreiras. Na Pedreira Vigné (Figura 1, Loc. 1), ocorrem duas gerações de brecha: a mais antiga é formada pela intrusão de magma sienítico com clastos compostos, predominantemente, de traquito e, subordinadamente, de rochas metamórficas, englobados na matriz sienítica; a mais nova é originada de erupção vulcânica, com clastos de álcali sienito e traquito (Motoki et al., 2006a; b). Em ambos os casos, a superfície do afloramento é lisa, não havendo saliência dos clastos sobre a matriz (Figura 3A). Brecha intrusiva similar ocorre, também, na pedreira desativada de brita, situada na entrada do Vale do Rio Dona Eugênia (Figura 1, Loc. 2). Esse afloramento, também, expõe a superfície sem saliência dos clastos.

No leito de rios, tal como do vale profundo do rio Dona Eugênia, encontram-se, localmente, rochas de baixo grau de intemperismo. A rocha piroclástica contém clastos de traquito e de álcali- 


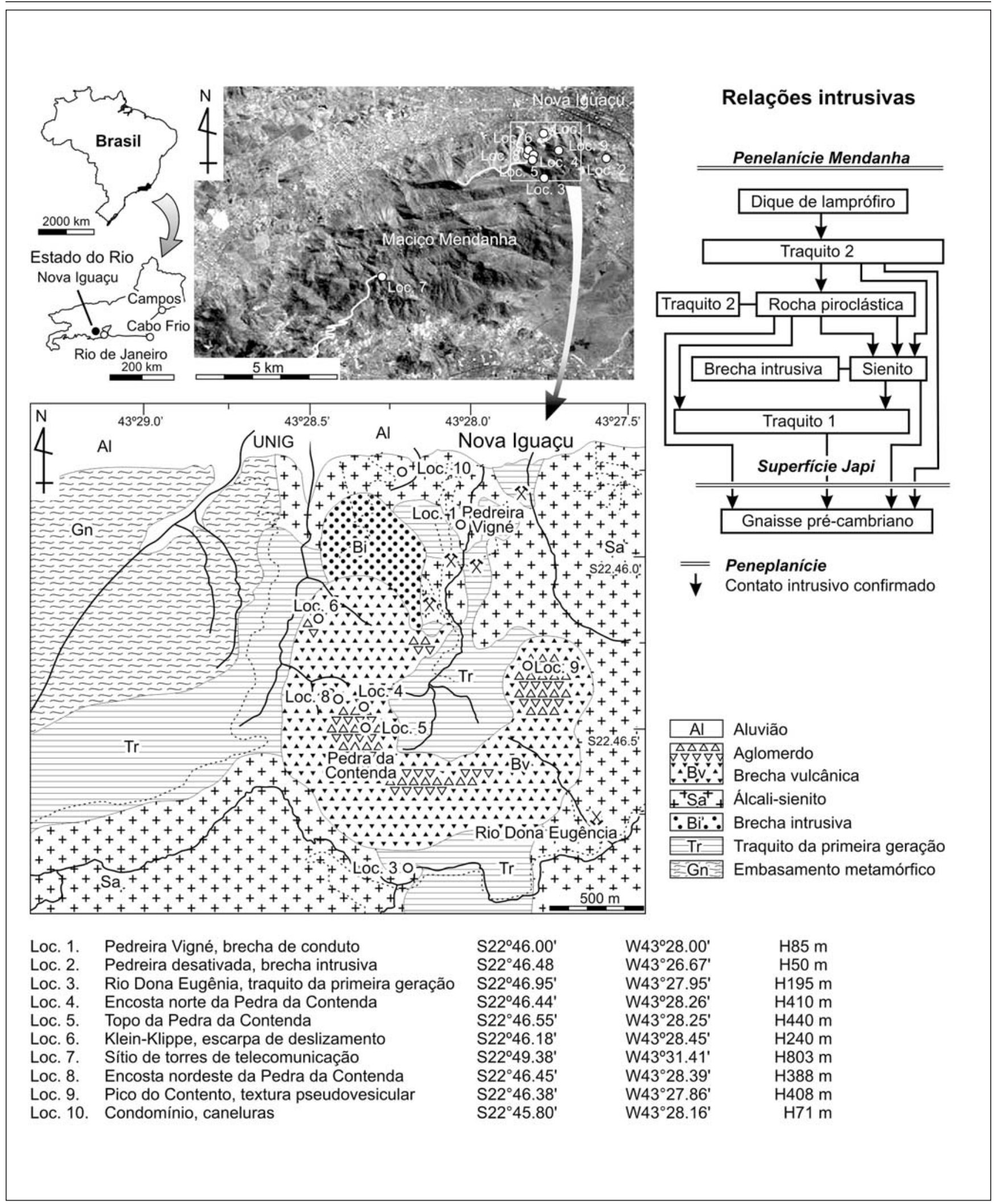

Figura 1 - Mapa geológico das rochas vulcânicas da área limítrofe do maciço Mendanha, Nova Iguaçu, RJ. A imagem de satélite é originada da EMBRAPA. No mapa, aglomerado corresponde às áreas com abundantes clastos de tamanho superior a $50 \mathrm{~cm}$. As expressões "traquito 1" e "traquito 2", que se encontram nas relações intrusivas, correspondem, respectivamente, ao traquito da primeira geração e da segunda geração. Os diques de traquito da segunda geração e de lamprófiro não aparecem na escala do mapa devido ao tamanho dos corpos muito pequeno. 
A. Case hardening

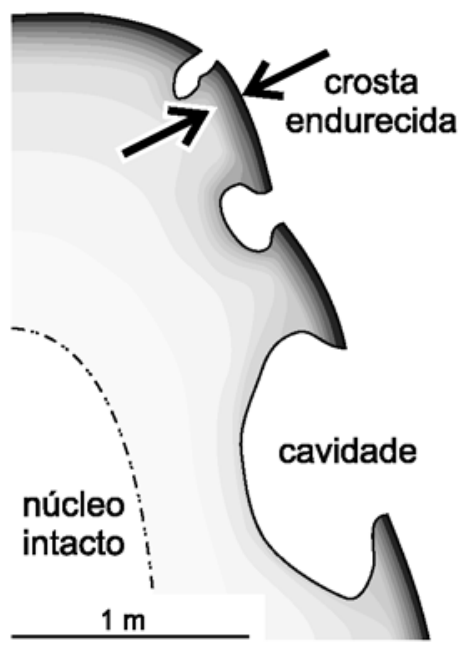

B. Dissociação de nefelina

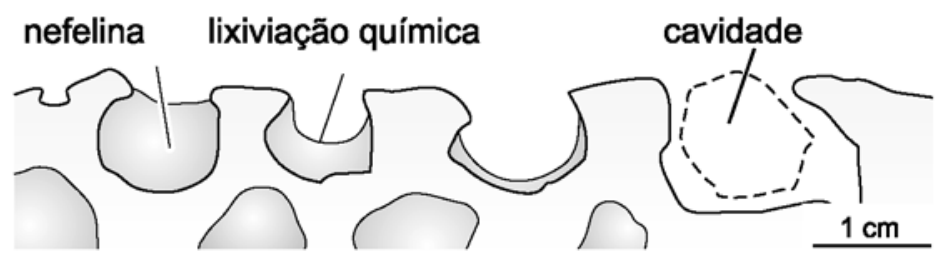

C. Dissociação de feldspato alcalino

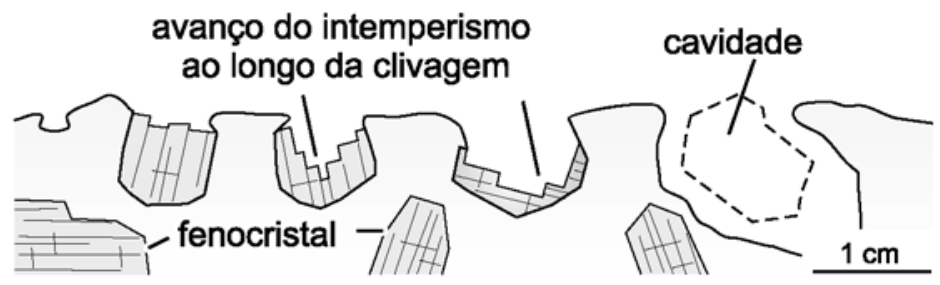

Figura 2 - Ilustração de processos intempéricos encontrados na superfície das rochas alcalinas da região de Nova Iguaçu: A) case hardening; B) dissociação mineral de nefelina na superfície de nefelina-sienito; C) dissociação de fenocristais de feldspato alcalino em traquito porfirítico. O processo de dissociação mineral avança da esquerda para direita nas Figuras B e C, culminando com a textura pseudovesicular.

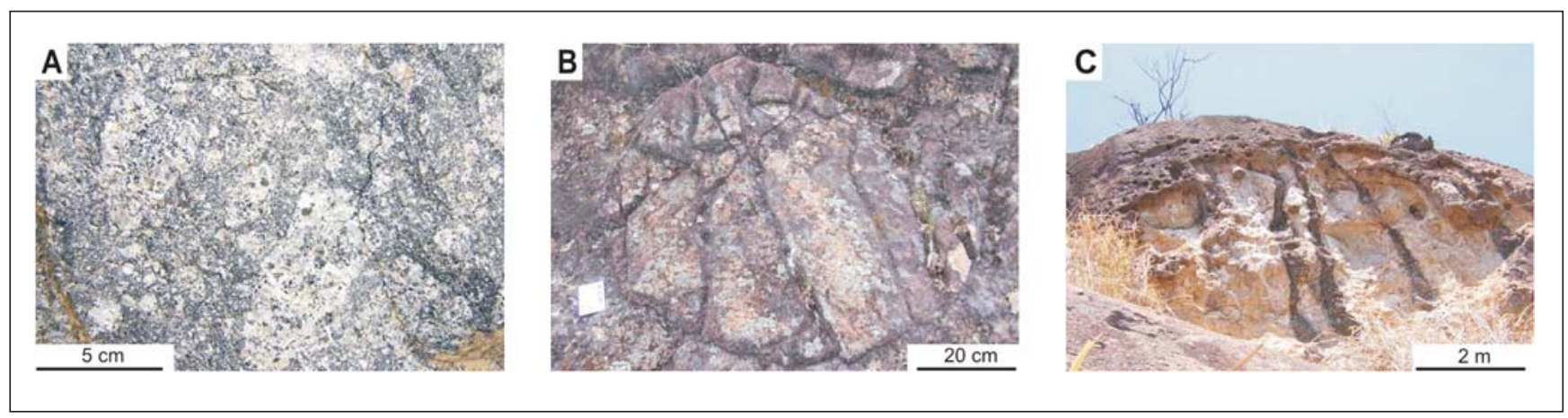

Figura 3 - Afloramentos de diferentes graus de intemperismo observados nas brechas vulcânicas de Nova Iguaçu: A) intacto, Pedreira Vigné, Loc. 1, Figura 1; B) grau médio, Pedra da Contenda, Loc. 4; C) grau alto, Klein-Klippe, Loc. 6.

sienito e ocorre como corpos intrusivos tabulares de configuração vertical, de forma similar a dique (Motoki \& Sichel, 2006). No Poço das Cobras (Figura 1, Loc. 3), observa-se afloramento de brecha vulcânica com camada superficial com intenso intemperismo de espessura milimétrica a centimétrica. Observa-se, eventualmente, pequena saliência dos clastos sobre a matriz com altura em torno de $1 \mathrm{~cm}$.

Os afloramentos de intemperismo de grau médio estão expostos no topo de morros (Figura 3B). Na Pedra da Con- tenda (Figura 1, Loc. 4), encontra-se um afloramento com superfície intensamente intemperizada de alguns centímetros de espessura. Efeitos de intemperismo menos intenso por infiltração profunda através da matriz atingem, pelo menos, alguns metros de profundidade. Os clastos expostos são constituídos, predominantemente, por traquito de tamanho variável, desde milimétrico até $70 \mathrm{~cm}$, apresentando saliência centimétrica sobre a matriz. Nesse afloramento, o intemperismo forma várias feições características nos clastos. O tamanho da saliência está geralmente, relacionado ao do clasto, sendo que os tamanhos são classificados, descritivamente, em 4 tipos: aqueles que se encontram nos clastos menores do que $5 \mathrm{~cm}$; de $5 \sim 30 \mathrm{~cm}$; de 30 60cm; maiores do que $60 \mathrm{~cm}$.

Os clastos de tamanho inferior a 5 cm apresentam saliência de $1 \mathrm{a} 2 \mathrm{~cm}$, mostrando superfície irregular (Figura 4A, setas pretas). Esse fenômeno pode ser atribuído, tanto à preservação da forma original dos clastos, quanto ao efeito intempérico.

Os clastos de 5 a $30 \mathrm{~cm}$ apresentam a saliência em torno de $2 \mathrm{~cm}$, que aumen- 
Akihisa Motoki et al.

ta com o tamanho dos mesmos e cuja superfície é, relativamente, regular (Figura 4B). O diâmetro dos clastos é muito maior do que a saliência, portanto a superfície semiplanar não corresponde à superfície original dos clastos, mas ao perfil de seus cortes (Figura 4B, seta de cor laranja). A saliência do clasto relativo à matriz é devida a case hardening.

Os clastos maiores do que $30 \mathrm{~cm}$, como encontrados no afloramento na proximidade do topo da Pedra de Contenda (Figura 1, Loc. 5), mostram superfície relativamente lisa, com a margem caracterizada por reentrância centimétrica entre as superfícies do clasto e da matriz (Figura 4C, seta verde). Essa feição pode ser atribuída ao contraste da resistência entre a superfície semiplanar do clasto endurecida por case hardening e a subsuperfície não endurecida do mesmo por core softening.

Alguns clastos grandes, maiores do que $60 \mathrm{~cm}$, mostram uma feição especial. Na margem dos clastos, até $2 \mathrm{~cm}$ a partir do contato, observa-se uma saliência linear que contorna a borda dos clastos (Figura 4D, setas vermelhas). No lado interior, ocorre uma zona com suave reentrância de largura aproximada de $5 \mathrm{~cm}$ (Figura 4D, 5B, setas verdes). $\mathrm{Na}$ parte central, ocorre uma saliência suave, de altura centimétrica e com forma subcircular e, na sua subsuperfície, encontra-se o núcleo remanescente intacto (setas azuis). Essa feição não é devida, simplesmente, ao intemperismo que atuou na superfície do afloramento: a saliência da margem é atribuída a case hardening na superfície dos clastos e a

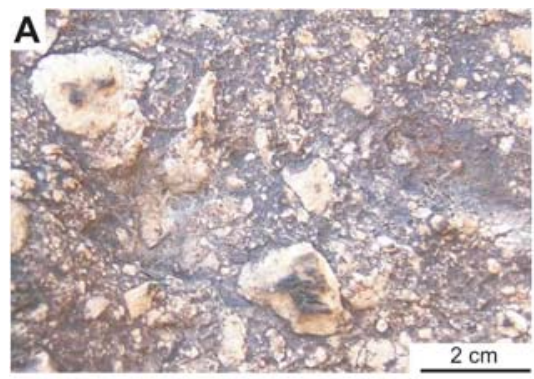

A. $<5 \mathrm{~cm}$

B. $5 \sim 30 \mathrm{~cm}$

C. $30 \sim 60 \mathrm{~cm}$
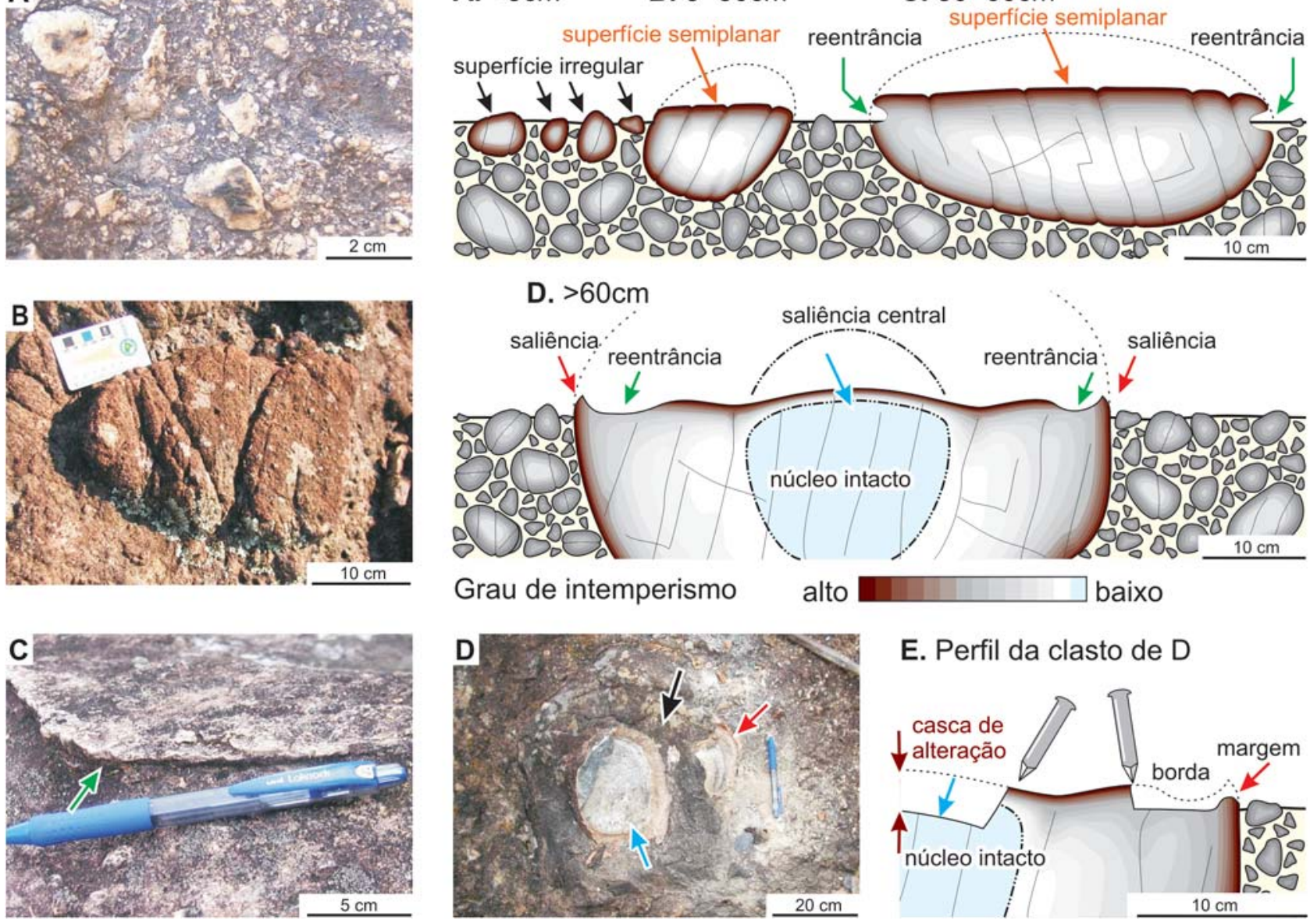

E. Perfil da clasto de D

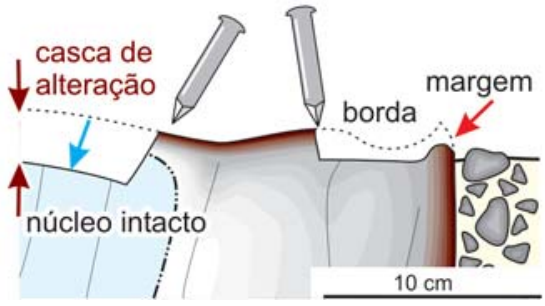

Figura 4 - Ilustração esquemática de perfis explicativos dos processos intempéricos de clastos e matriz de brecha vulcânica e seus exemplos: A) clastos de tamanho inferior a $5 \mathrm{~cm}$ com perfil irregular, tais como da Pedra de Contenda, Loc. 4; B) clastos de $5 \sim 30 \mathrm{~cm}$ com perfil relativamente liso, Loc. 4; C) clastos de 30 60 cm com perfil liso, com a reentrância lateral na margem por core softening, Topo da Pedra da Contenda, Loc. 5; D) clastos maiores do que $60 \mathrm{~cm}$ com apresentação da saliência (seta vermelha) e reentrância (seta verde) ao longo no contorno e núcleo não intemperizado (seta azul), Loc. 4. As fotos A, B, C e D correspondem, respectivamente, aos exemplos dos dos casos A, B, C e D da ilustração. 
reentrância adjacente, ao core softening da subsuperfície dos clastos.

Em escarpas verticais, resultantes do deslizamento do regolito, ocorrem afloramentos de alto grau de intemperismo. Nesses afloramentos, tal como de Klein-Klippe (Figura 1, Loc. 6), observam-se feições intempéricas peculiares dos clastos grandes. Um clasto de tamanho aproximado de $80 \mathrm{~cm}$ mostra feição similar à da Figura 4D, porém o núcleo intacto é exposto, diretamente, na superfície do afloramento (Figura 5A, seta azul). A saliência da margem formada pelo case hardening (seta vermelha) é desenvolvida não simplesmente em direção perpendicular à superfície do afloramento (Figura 5B, D, seta vermelha), mas se curva para o centro do clasto (Figura 5D, seta preta). Portanto, interpreta-se que o case hardening se desenvolve ao longo da nova face do clasto, que foi exposta por deslizamento.

As feições anteriormente citadas sugerem duas etapas de case hardening. A primeira teria envolvido a superfície do clasto todo, conforme a ilustração da Figura 5C, antes mesmo do deslizamento. A segunda teria ocorrido depois que o clasto foi quebrado, em virtude do deslizamento, quando, então, formou-se um prolongamento do case hardening (Figura $5 \mathrm{E}$, seta preta), que resultaria no recobrimento da superfície nova.

A exposição regolítica da Loc. 6 mostra o case hardening e core softening em escala de afloramento (Figura 3C). Na parte superior, de cor escura, observam-se o case hardening originado, provavelmente, de cimentação dos hidróxidos de ferro e magnésio. Esses materiais foram lixiviados pela atividade da água superficial, formando três faixas verticais de cor escura, cobrindo a parte inferior do afloramento de cor clara, que corresponde à cavidade de core softening.

\section{Dissociação mineral por intemperismo}

A dissociação mineral de nefelina é observada, tipicamente, na superfície de nefelina-sienito. No maciço Mendanha,

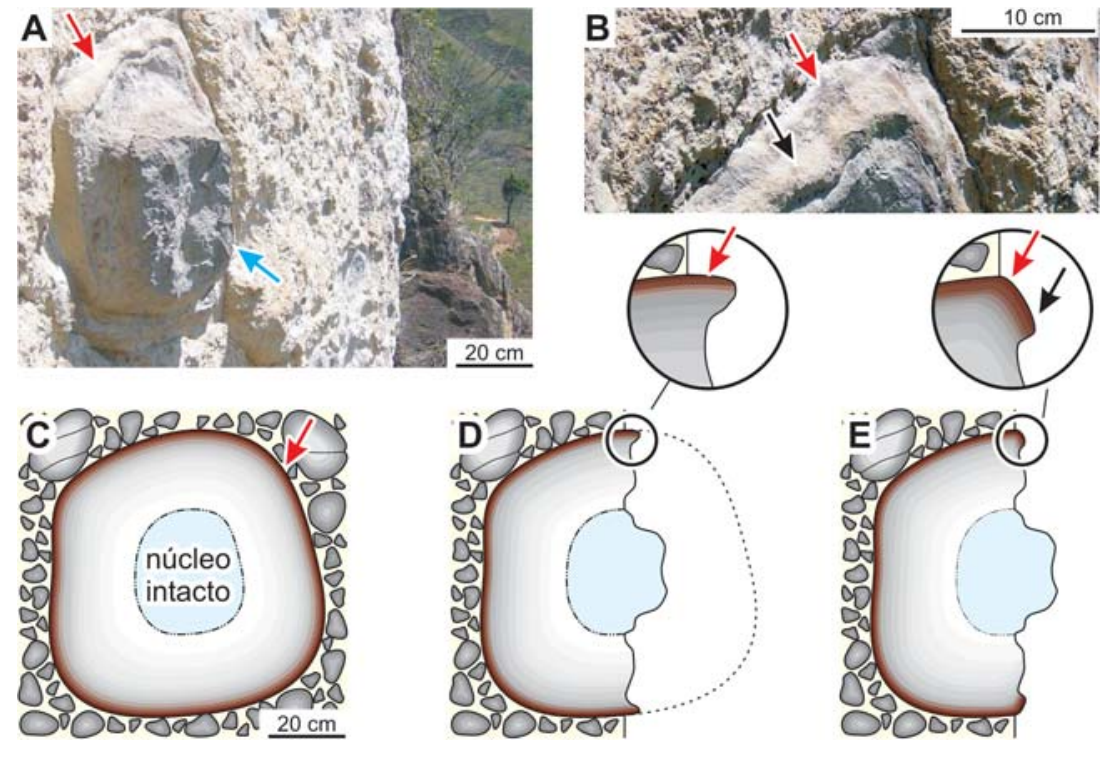

Figura 5 - Imagens (A, B) de um clasto traquítico com $80 \mathrm{~cm}$ de diâmetro exposto na Klein-Klippe (Figura 1, Loc. 6) e, as ilustrações esquemáticas (C, D, E) de processo de desenvolvimento de case hardening antes e depois da exposição de corte do clasto: A) imagem geral do clasto, apresentando a exposição do núcleo intacto (seta azul); B) detalhe da borda do clasto; C) desenvolvimento de case hardening ao longo da margem do clasto (seta vermelha); D) exposição de corte do clasto resultante de deslizamento; E) desenvolvimento de case hardening ao longo da superfície nova, após exposição do afloramento (seta preta).

o nefelina-sienito ocorre na parte oeste, tal como no Pico de Marapicu, onde ocorre a jazida de rocha ornamental "Granito Cinza-Ás-de-Paus”. Na peneplanície Mendanha, que compõe o topo do maciço (Motoki et al., 2006a), na proximidade do sítio das torres de comunicação (Figura 1, Loc. 7), observam-se os blocos arredondados de nefelina-sienito com superfície intemperizada, apresentando numerosas cavidades de tamanho de 1 a 3 cm (Figura 6A).

A dissociação dos fenocristais de feldspato alcalino e a formação da estrutura pseudovesicular são observadas, expressivamente, na superfície intemperizada do traquito da primeira geração, que é a rocha traquítica predominante dessa região. Na encosta noroeste da Pedra da Contenda (Figura 1, Loc. 8), encontra-se um bloco rolado de traquito porfirítico, que apresenta a superfície com cavidades de tamanho aproximado de $1 \mathrm{~cm}$ (Figura 6B). Na brecha vulcânica que se expõe no Pico do Contento (Figura 1, Loc. 9), observam-se os clastos altamente intemperizados com a superfície repleta de cavidades (Figura 6C). A estrutura pseudovesicular está bem desenvolvida e a feição pode ser confundida, à primeira vista, com estrutura vesicular de spatter, escória e bomba vulcânica. Entretanto a subsuperfície com relativamente baixo grau de intemperismo revela que esses clastos não são vesiculares, mas, sim, maciços. Na parte inferior direita da Figura 6C, observa-se o processo inicial de dissociação de fenocristal de feldspato alcalino (seta verde).

\section{Discussões}

A maioria dos clastos da brecha vulcânica de Nova Iguaçu é caracterizada por desenvolvimento de fraturas paralelas de intervalo de 5 a $20 \mathrm{~cm}$. As fraturas aparecem, geralmente, como reentrâncias lineares nos afloramentos intemperizados (Figuras 4B; 7A). Eventualmente, essas fraturas se manifestam como saliências originadas de case hardening nos clastos intensamente intemperizados (Figura 7B). 


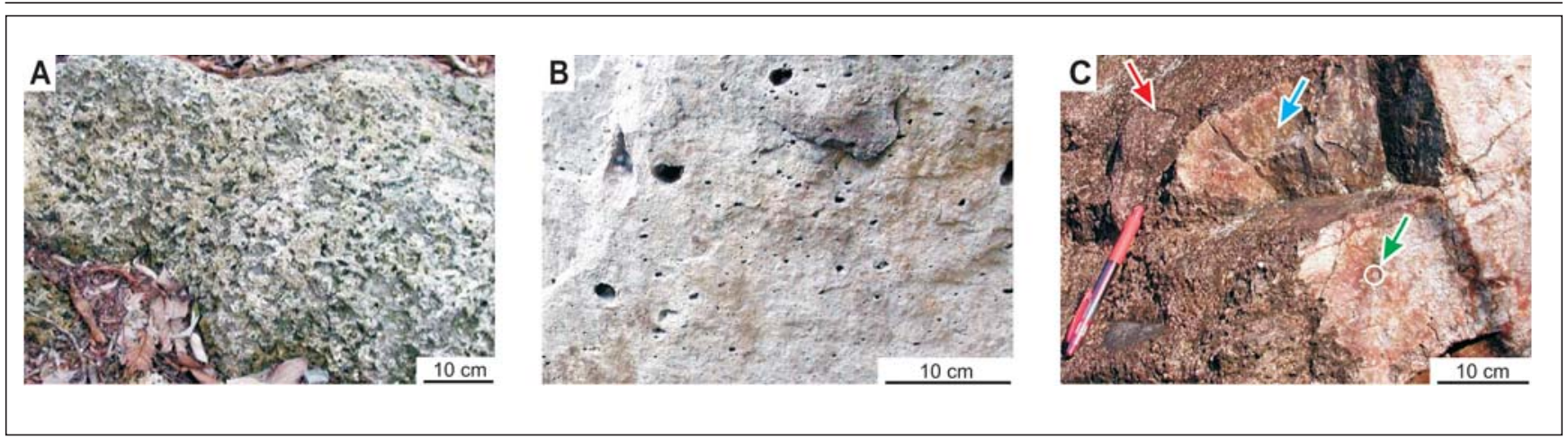

Figura 6 - Exemplos de dissociação mineral e formação de cavidades na superfície das rochas alcalinas da região de Nova Iguaçu: A) matacão de nefelina-sienito com cavidades formadas pela dissociação de nefelina, sítio de torres de telecomunicação, Loc. 7, Figura 1; B) cavidades formadas na superfície de traquito porfirítico por dissociação de fenocristais de feldspato alcalino, bloco rolado na encosta nordeste da Pedra da Contenda, Loc. 8; C) superfície intemperizada de textura pseudovesicular (seta vermelha), interior do maciço (seta azul) e processo inicial da dissociação mineral (seta verde), observados em traquito exposto no Pico do Contento, Loc. 9.

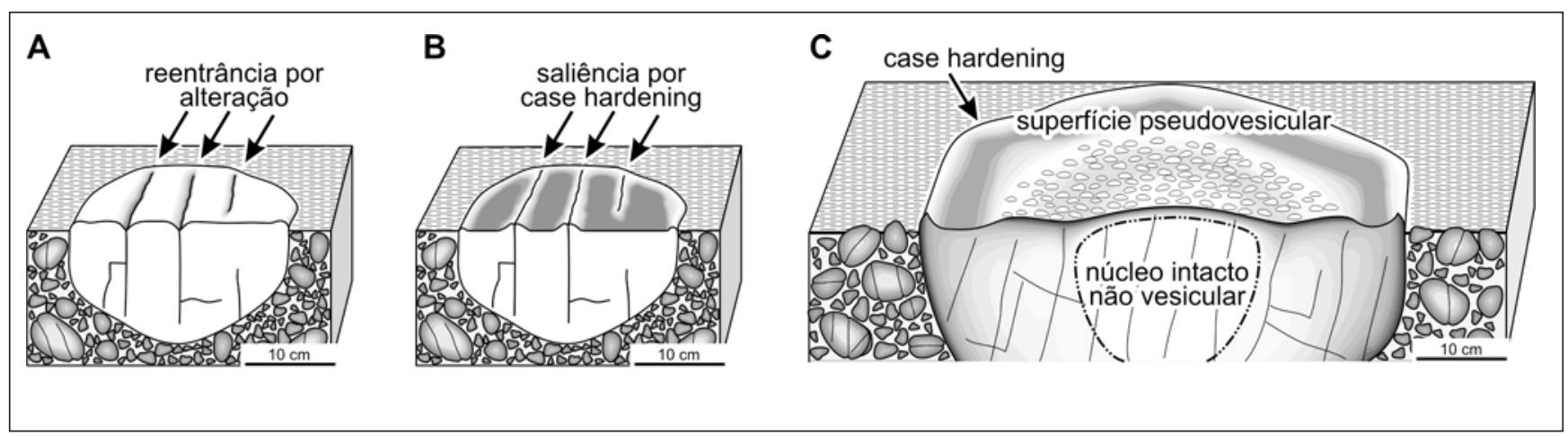

Figura 7- Ilustração esquemática das feições intempéricas de clastos fraturados: A) intemperismo de grau médio com reentrâncias lineares ao longo de fraturas; B) intemperismo de grau alto com saliências lineares ao longo de fraturas por case hardening; C) ocorrência de saliência ao longo do contorno por case hardening e estrutura pseudovesicular por dissociação mineral na superfície.

Alguns clastos apresentam mais de uma estrutura gerada por intemperismo. Quando ocorre a associação de case hardening (Figura 4D) e estrutura pseudovesicular (Figura 6C), o clasto adquire aspecto semelhante à bomba vulcânica (Figura 7C), onde a crosta endurecida parece ser a margem de resfriamento. Clastos com fraturas ramificadas, por outro lado, mostram feição parecida à superfície de bomba do tipo crosta-depão (Figura 8).

A estrutura pseudovesicular é observada, também, nos xenólitos de traquito porfirítico capturado pelo álcali-sienito (Figura 1, Loc. 10). O álcali-sienito desse afloramento mostra uma outra feição intempérica denominada "caneluras”. Essa feição corresponde aos sulcos marcados na superfície de afloramento rochoso, originada de corrosão química da rocha pela acidez da água da chuva. As caneluras são observadas, comumente, em nefelina-sienito e pulaskito (e.g. Motoki, 1986) e têm largura de 50 $\mathrm{cm}$ a $1 \mathrm{~m}$ e profundidade de 20 a $30 \mathrm{~cm}$. As caneluras da Loc. 10 têm largura menor, de 20 a $40 \mathrm{~cm}$, e profundidade de 20 a $30 \mathrm{~cm}$.

Trabalhos anteriores basearam-se na existência de bombas vulcânicas como uma importante justificativa da existência de um edifício vulcânico (Klein \& Vieira, 1980b; Vieira \& Klein, 2004; Ghizi et al., 2004; Silveira et al., 2005; Valente et al., 2005). Os clastos em discussão têm forma arredondada e saliência ao longo da margem de altura centimétrica, e correspondem às feições das Figuras 4D, 5 e 7C. Os clastos interpretados como "ejetólitos escolíceos” ou feição similar a “spatter” (Klein \& Vieira, 1980b; Klein et

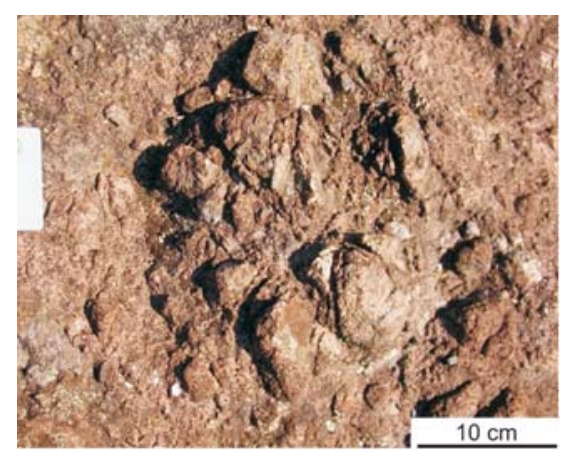

Figura 8 - Clasto traquítico intemperizado com fraturas ramificadas, brecha vulcânica da Pedra da Contenda (Loc. 9, Figura 1).

al., 2001) correspondem aos clastos com estrutura pseudovesicular. Os clastos arredondados de tamanho pequeno, até $15 \mathrm{~cm}$ de diâmetro, sob intenso efeito de intemperismo, apresentam forma desta- 
cada de case hardening e core softening e correspondem às "bombas ocas" de Klein et al. (1984).

As estruturas intempéricas são complexas e, portanto, as descrições dos clastos intemperizados devem ser realizadas com muito cuidado, não somente pela observação da superfície alterada do afloramento, como também do interior, que se apresenta com menor grau de intemperismo, sobretudo do núcleo intacto.

\section{Conclusões}

Feições intempéricas dos clastos traquíticas de brecha vulcânica de Nova Iguaçu são caracterizadas por case hardening e core softening. A crosta endurecida é encontrada tanto na superfície do afloramento quanto dos clastos. Alguns clastos grandes possuem núcleo intacto, apresentando estrutura de intemperismo esferoidal.

A dissociação intempérica de fenocristais da superfície dos clastos traquíticos gera uma estrutura, aparentemente, vesicular, denominada pseudovesicular. Clastos com uma saliência na borda decorrente de case hardening e estrutura pseudovesicular resultante da dissociação mineral apresentam aspecto similar ao perfil de bomba vulcânica. Quando os clastos possuem fraturas altamente ramificadas, eles se apresentam com feição similar à superfície de bomba de crosta-de-pão. Entretanto o núcleo intacto desses clastos é maciço e não apresentam as feições características de bomba vulcânica, tal como vesiculação e deformação plástica durante o vôo. Essas observações são desfavoráveis à hipótese do Vulcão de Nova Iguaçu, que adota a origem extrusiva dos clastos como um argumento fundamental.

\section{Agradecimentos}

As etapas de campo foram realizadas com a participação dos alunos colaboradores. Os autores agradecem aos alunos Daniel Aderino, do Curso de Geologia da UERJ, Ariadne Marra de Souza da mesma instituição, e Kenji Freire Motoki, da Associação Educacional Plínio Leite.

\section{Referências bibliográficas}

CAMPBELL, S.W. Chemical weathering associated with tafoni at Papago Park, Central Arizona. Earth Surface Process and Landforms, v. 24, p. 271-278, 1999.

DORN, R.L. Case hardening. In: GOUDIE, A.S. Ed. Encyclopedia of Geomorphology. London: Loutledge, 2004. p.118-119.

FARMER, J.D. Case-hardening of rocks on Mars: evidence for water-mediated weathering processes. Abstracts of annual meeting of the Geological Society of America, Salt Lake City, paper 223-5, CD, 2005.

GHIZI, A., MANSUR, K., VIEIRA, A.C. Geoparque do Vulcão de Nova Iguaçu. Homepage do DRM, http://www.drm.rj.gov.br/item.asp?chave=109, 2004.

KLEIN, V.C. O vulcão alcalino de Nova Iguaçu (Estado do Rio de Janeiro): controle estrutural e processo de erupção. Rio de Janeiro: Universidade Federal do Rio de Janeiro. 1993. (Tese de Doutorado).

KLEIN, V.C., ÁVILA, C.A., DAYAN, H. Bombas “crosta-de-pão” (bread crust) nos depósitos piroclásticos do vulcão de Nova Iguaçu, Rio de Janeiro. Bol. Res. $7^{\circ}$ Simp. Geol. Sudeste, CD, Rio de Janeiro, SBG, 2001.

KLEIN, V.C., VALENÇA, J.G., VIEIRA, A.C. Ignimbritos do vulcão de Nova Iguaçu e da "Chaminé do Lamego", Rio de Janeiro. In: In: CONGRESSO BRASILEIRO DE GEOLOGIA, 33. Anais... p. 4346-4354, Rio de Janeiro, SBG, 1984.

KLEIN, V.C., VALENÇA, J.G. Mecanismo de colocação de brechas fluidizadas na área de Cabuçu (complexo alcalino do Mendanha), Rio de Janeiro. In: In: CONGRESSO BRASILEIRO DE GEOLOGIA, 33. Anais... p. 4355-4361. Rio de Janeiro, SBG, 1984.

KLEIN, V.C., VIEIRA, A.C. Uma chaminé vulcânica na serra de Madureira, Nova Iguaçu, Rio de Janeiro. Academia Brasileira de Ciências, Rio de Janeiro, v. 52, p. 200, 1980a. (Comunicação Breve).

KLEIN, V.C., VIEIRA, A.C. Vulcões do Rio de Janeiro: breve geologia e perspectivas. Mineração Metalurgia, v. 419, p. 44-46, 1980b.

MOTOKI, A. Geologia e petrologia do maciço Alcalino da Ilha de Vitória, SP. São Paulo: Instituto de Geociências da Universidade de São Paulo, 1986. (Tese de Doutorado).

MOTOKI, A., ADRIANO, L., MELO, D.P., FREITAS, A. Edifícios vulcânicos e corpos subvulcânicos, de acordo com os níveis de denudação: exemplos do Brasil e da Argentina. In: CONGRESSO BRASILEIRO DE GEOLOGIA, 42. Anais... CD, Araxá, SBG, 2004.

MOTOKI, A., NETO, A.M., SICHEL, S.E., AIRES, J.R., SOARES, R., LOBATO, M. História de denudação regional e profundidade de posicionamento geológico das rochas vulcânicas de Nova Iguaçu, maciço Mendanha, RJ: constituintes de um vulcão ou corpos subvulcânicos? In: CONGRESSO BRASILEIRO DE GEOLOGIA, 43. Anais... SBG, Aracaju, 136, 2006a.

MOTOKI, A., SICHEL, S., FONSECA, L.G., SILVA, M.S., ALMEIDA, F.S.S., CORRALES, F. Relação entre as texturas de rochas vulcânicas e estruturas de corpos vulcânicos e subvulcânicos: exemplos do Brasil, Argentina e Chile. In: SIMPÓSIO DE VULCANISMO E AMBIENTES ASSOCIADOS, 3. Anais... Cabo Frio, p. 387-392, 2005.

MOTOKI, A., SICHEL, S.E. Avaliação de aspectos texturais e estruturais de corpos vulcânicos e subvulcânicos e sua relação com o ambiente de cristalização, com base em exemplos do Brasil, Argentina e Chile. REM - Revista Escola de Minas, v. 59, n. 1, p. 13-23, 2006.

MOTOKI, A., SICHEL, S.E., AIRES, J.R., SOARES, R., LOBATO, M. Feição similar à disjunção colunar horizontal do corpo traquítico de rochas vulcânicas de Nova Iguaçu, RJ, e a consideração sobre sua gênese.In: CONGRESSO BRASILEIRO DE GEOLOGIA, 43. Anais... SBG, Aracaju, 136, 2006b

SILVEIRA, L.S., DUTRA, T., VALENTE, S.C., RAGATKY, D.C., Modelos eruptivos preliminares para o Complexo Vulcânico de Nova Iguaçu, RJ. In: SIMPÓSIO DE VULCANISMO E AMBIENTES ASSOCIADOS, 3. Anais... p. 333-337, 2005.

ULBRICH, H.H.G.J., GOMES, C.B. Alkaline rocks from continental Brazil. Earth-Science Reviews. v. 17, p. 135-154, 1981.

VALENTE, S.C., MELLO, E.F., PALERMO. Geologia de uma porção do complexo vulcânico de Nova Iguaçu limítrofe à área de lavra da pedreira Vigné, Nova Iguaçu, RJ. Relatório final. Ministério Público. Nova Iguaçu, 2005. 72 p.

VIEIRA, A.C., KLEIN, V.C. Vulcão de Nova Iguaçu, o vulcão brasileiro. CREA-RJ, 2004. $10 \mathrm{p}$.

Artigo recebido em 04/09/2006 e aprovado em 06/03/2007. 